Volume (1), Nomor (2), Bulan 2021, 70-82

ISSN. 2807-3339

journal homepage: https://mahardhika.or.id/jurnal/index.php/jpdm

\title{
Tingkat Keaktifan Guru Penjas Pada Masa Pandemi Covid-19 di SMP/MTS Se-Kecamatan Tanggungharjo
}

\author{
${ }^{1}$ Helmin Saraswati, ${ }^{2}$ Agus Wiyanto, ${ }^{3}$ Utvi Hinda Zhannisa \\ ${ }^{123}$ Pendidikan Jasmani Kesehatan dan Rekreasi, Universitas PGRI Semarang \\ ${ }^{1}$ E-mail: helminsaras98@gmail.com \\ ${ }^{2}$ E-mail: aguswiyanto7@gmail.com \\ ${ }^{3}$ E-mail utvihindazhannisa@gmail.com
}

\section{A R T I C L E I N F O}

\section{Article history:}

Received 2021-11-20

Revised 2021-11-24

Accepted 2021-11-29

Keywords:

Guru, Penjas, Keaktifan, Covid-19

\begin{abstract}
A B S T R A C T
The background of this research problem is that some physical education teachers have difficulty in learning physical education during the covid-19 pandemic. The purpose of this study was to determine the level of activity of physical education teachers during learning during the covid 19 pandemic. The type of research used is qualitative research.. Informants in this study were principals/deputy principals, and physical education teachers. Data collection techniques in this study used several techniques, namely observation, interviews, and documentation. The data validity technique in this research is source triangulation. The analysis was carried out using an interactive analysis model. The results of this study indicate that in the results of observations in the form of teaching and learning processes through WhatsApp Group and the results of interviews that have been conducted by researchers that physical education teachers in several schools that have been studied in teaching and learning activities during online learning are very limited and have not run optimally. There are constraint factors that make teaching and learning activities not run well, several obstacles to students that make teaching and learning activities less run optimally, such as students who do not have cellphones, lack of internet network, students who are lazy when learning, students who are bored and lack of enthusiasm during online learning, students who do not respond to the teacher during learning. The conclusion of this study is that the level of activity of physical education teachers in physical education learning during the COVID19 pandemic in SMP/MTs throughout the District of Tanggungharjo has not run optimally..
\end{abstract}

Keywords: activity level, physical education teacher, covid 19 pandemic 


\begin{abstract}
Abstrak
Latar belakang masalah penelitian ini beberapa guru penjas mengalami kesulitan dalam pembelajaran penjas masa pandemi covid-19. Tujuan penelitian ini untuk mengetahui tingkat dari keaktifan guru penjas pada saat pembelajaran masa pandemi covid 19. Jenis penelitian yang digunakan yaitu penelitian kualitatif. Informan dalam penelitian ini adalah kepala sekolah/wakil kepala sekolah, dan guru penjas. Teknik pengumpulan data dalam penelitian ini menggunakan beberapa teknik yaitu observasi, wawancara, dan dokumentasi. Teknik keabsahan data dalam penelitian ini adalah triangulasi sumber. Analisis yang dilakukan menggunakan model analisis interaktif. Hasil penelitian ini menunjukan bahawa dalam hasil observasi berupa proses belajar mengajar melalui WhatsApp Group dan hasil wawancara yang telah dilakukan peneliti bahwa guru penjas di beberapa sekolah yang sudah diteliti dalam kegiatan belajar mengajar selama pembelajaran daring sangatlah terbatas dan belum berjalan dengan maksimal. Adanya faktor kendala yang membuat kegiatan belajar mengajar menjadi tidak berjalan dengan baik, beberapa kendala pada siswa yang membuat kegiatan belajar mengajar kurang berjalan dengan maksimal yaitu seperti siswa yang tidak memiliki handphone, jaringan internet yang kurang, siswa yang malas saat pembelajaran, siswa yang bosan dan kurang semangat pada saat pemebelajaran daring, siswa yang tidak merespon guru pada saat pembelajaran berlangsung. Kesimpulan penelitian ini adalah tingkat keaktifan guru penjas dalam pembelajaran penjasorkes pada masa pandemi COVID-19 di SMP/MTS seKecamatan Tanggungharjo belum berjalan dengan maksimal.
\end{abstract}

Kata Kunci : tingkat keaktifan, guru penjas, pandemi covid 19

\title{
PENDAHULUAN
}

Pendidikan jasmani merupakan pembelajaran yang menggunakan aktivitas jasmani sebagai media yang bertujuan untuk mengembangkan kebugaran jasmani dan juga ketrampilan gerak. Peran guru pada saat pembelajaran sangat mempengaruhi peserta didik, guru yang aktif akan membuat peserta didik menjadi aktif. Pada saat ini pandemi covid 19 memberikan dampak yang cukup dalam bagi manusia. Proses Kegiatan Belajar Mengajar (KBM) di sekolah menjadi salah satu dampak dalam pandemi ini. Pola pembelajaran di Indonesia yang semula tatap muka secara langsung menerapkan PJJ (Pembelajaran Jarak Jauh). Hal ini juga berdampak bagi pembelajaran penjas di sekolah. Berlangsungnya pembelajaran jarak jauh memanfaatkan teknologi informasi. Pada saat pembelajaran jarak jauh berlangsung guru sebisa mungkin harus membuat peserta didik aktif dan kreatif dalam pembelajaran jarak jauh.

Berdasarkan hasil observasi yang dilakukan oleh peneliti di SMP/MTS se Kecamatan Tanggungharjo, peneliti mengamati proses pembelajaran berlangsung hal tersebut bisa dilihat apakah guru penjas aktif dalam kegiatan belajar mengajar/apakah guru penjas tidak aktif dalam kegiatan belajar 
mengajar. Terdapat beberapa kendala pada saat proses belajar mengajar berlangsung diantaranya siswa tidak mengerjakan tugas, terlambat mengumpulkan tugas, siswa yang tidak merespon guru pada saat pembelajaran, presensi kehadiran siswa yang kurang terpenuhi pada saat pembelajaran jarak jauh.

Pembelajaran yang aktif dan kreatif diperlukan guru yang aktif dalam pembelajaran guna mencapai tujuan pendidikan yang mampu mengantarkan peserta didik menjadi generasi yang mampu memimpin kemajuan bangsa dan Negara dalam hal ini peneliti mengambil judul tingkat keaktifan guru penjas pada masa pandemi Covid-19 di SMP/MTS se-Kecamatan Tanggungharjo.

\section{METODE}

Metode penelitian ini menggunakan metode penelitian kualitatif deskriptif, tujuan dari peneliti ini ingin mendeskripsikan terkait tingkat keaktifan guru penjas dalam pembelajaran penjaskes pada masa pandemi covid-19, dan penelitian ini akan dilakukan di Sekolah Menengah Pertama/Madrasah Tsanawiyah (SMP/MTS) Sederajat Se-Kecamatan Tanggungharjo.

Lokasi dari penelitian ini dilakukan di Sekolah Menengah Pertama/Madrasah Tsanawiyah (SMP/MTS) Sederajat Se-Keamatan Tanggungharjo, penelitian dilakukan di SMP Negeri 1 Tanggungharjo, MTS Tajul Ulum, SMP Al Ishlah, MTS Miftahul Ulum, SMP IT At Taufiiqiyyah.

Fokus penelitian ini ditujukan kepada guru penjas dan kepala/wakil kepala sekolah guna untuk mengetahui bagaimana tingkat keaktifan guru penjas pada masa pandemi covid-19.

Penelitian ini menggunakan sumber data dari guru penjas dan kepala/wakil kepala sekolah SMP/MTS Sederajat Se-Kecamatan Tanggungharjo, penelitian ini untuk mengetahui tingkat keaktifan guru penjas pada masa pandemi covid-19. Disetiap sekolah penelitian ini mengambil 1 guru penjas dan 1 kepala/wakil kepala sekolah untuk dijadikan subjek pada penelitian ini.

\section{HASIL DAN PEMBAHASAN}

Berdasarkan data wawancara dengan guru penjas dan kepala sekolah/wakil kepala sekolah, peneliti mengamati adanya tingkat keaktifan guru penjas pada masa pandemi covid-19. Hal itu bisa dilihat dari hasil temuan peneliti dilapangan sebagai berikut :

1. Kepala sekolah/wakil kepala sekolah

a) Tanggapan pembelajaran daring di sekolah

1) SMP N 1 Tanggungharjo

Tanggapan kepala sekolah dalam pembelajaran daring pada saat wawancara kepala sekolah SMP N 1 Tanggungharjo menanggapi pembelajaran daring si sekolah dengan positif dan mendukung pemerintah perihal pembelajaran daring di sekolah.

2) MTS Tajul Ulum

Tanggapan kepala sekolah dalam pembelajaran daring pada saat wawancara di sekolah MTS Tajul Ulum guru kesulitan dalam mengondisikan siswa. Hal ini di karenakan adanya 
siswa yang tidak memiliki sarana dalam pebelajaran daring sehingga membuat guru mengalami kesulitan pada saat belajar mengajar berlangsung.

3) SMP Al Ishlah

Tanggapan dari wakil kepala sekolah dalam pembelajaran daring di SMP Al Ishlah pembelajaran daring belum sempurna pembelajaran dilakukan semi daring, karena adanya siswa yang tinggal di pondok pesantren.

4) MTS Miftahul Ulum

Tanggapan dari wakil kepala sekolah pembelajaran daring kurang efektif hal ini di karena adanya pembelajaran daring siswa harus memiliki sarana prasarana seperti handphone sendiri dan di MTS Miftahul Ulum tingkat ekonomi nya tidak sama.

5) SMP IT At Taufiiqiyyah

Tanggapan kepala sekolah tentang pembelajaran daring pembelajaran tidak bisa maksimal karena tidak bisa tatap muka secara langsung sehingga untuk membentuk karakter siswa tidak bisa maksimal apabila daring.

b) Aktifitas pembelajaran penjas dimasa pandemi

1) SMP Negeri 1 Tanggungharjo

Dari hasil wawancara dengan kepala sekolah bahwa aktifitas pembelajaran penjas sangatlah terbatas. Untuk aktifitas pembelajaran penjas daring ini hanya bisa bersifat teori, dan untuk praktik sangat tidak praktis.

2) MTS Tajul Ulum

Dari hasil wawancara dengan kepala sekolah aktifitas pembelajaran penjas di MTS Tajul Ulum banyak teori-teori dan apabila kegiatan praktik memang harus dilakukan siswa melakukan praktik melalui video.

3) SMP Al Ishlah

Dari hasil wawancara dengan wakil kepala sekolah aktifitas pembelajaran penjas dimasa pandemi guru memberikan materi-materi ringan dan untuk praktik siswa ditugaskan untuk membuat video. Dan untuk anak yang tinggal di pondok pesantren siswa datang secara langsung ke sekolahan untuk mengambil tugas.

4) MTS Miftahul Ulum

Dari hasil wawancara wakil kepala sekolah aktifitas pembelajaran penjas di MTS Miftahul Ulum dilakukan secara daring.

5) SMP IT At Taufiiqiyyah

Dari hasil wawancara kepala sekolah aktifitas pembelajaran penjas kurang efektif karena penyampaian materi-materi dan pelaksanaan kegiatan praktik tidak bisa maksimal apabila dilaksanakan secara daring.

c) Harapan dari pembelajaran penjas masa pandemi

1) SMP Negeri 1 Tanggungharjo

Harapan dari kepala sekolah dalam wawancara dapat di katakan bahwa kepala sekolah berharap dengan kuota yang sangat terbatas bisa dihadirkan untuk hal-hal tertentu yang tidak bisa dilaksanakan secara daring.

2) MTS Tajul Ulum

Harapan dari kepala sekolah dalam wawancara dapat di katakan bahwa kepala sekolah menginginkan dengan adanya pembelajaran penjas daring di masa pandemi siswa harus tetap berolahraga walaupun di rumahnya masing-masing dan harus menjaga imun tubuh agar tetap 
sehat.

3) SMP Al Ishlah

Harapan dari wakil kepala sekolah dalam wawancara dapat di katakan bahwa di masa pandemi ini kepala sekolah menginginkan siswa sehat dan siswa harus tetap berolahraga meskipun pembelajaran tidak ada tatap muka secara langsung.

4) MTS Miftahul Ulum

Harapan dari wakil kepala sekolah dalam wawancara dapat di katakan bahwa wakil kepala sekolah menginginkan pembelajaran penjas harus ada walaupun itu daring dan siswa mempraktikan sendiri-sendiri di rumah .

5) SMP IT At Taufiiqiyyah

Harapan dari kepala sekolah dalam wawancara dapat di katakan bahwa siswa harus sehat, harus berolahraga, dan harus belajar walaupun tidak bisa tatap muka secara langsung.

d) Guru penjas dalam mengelola kelas

1) SMP Negeri 1 Tanggungharjo Schoology.

Guru penjas dalam mengelola kelas dengan menggunakan applikasi WhatsApp dan

2) MTS Tajul Ulum

Guru penjas dalam mengelola kelas dengan menggunakan applikasi WhatsApp dan Google form.

3) SMP Al Ishlah

Guru penjas sebelum adanya pandemi sudah baik dalam mengelola kelas. Dan dimasa pandemi guru penjas mengalami kesulitan pada anak yang tinggal di pondok pesantren karena siswa pondok tidak di perbolehkan menggunakan handphone jadi kegiatan pembelajaran untuk anak yang di pondok pesantren langusng datang ke sekolah untuk mengambil tugas.

4) MTS Miftahul Ulum

Guru penjas dalam mengelola kelas dengan menggunakan aplikasi WhatsApp.

5) SMP IT At Taufiiqiyyah

Guru penjas dalam mengelola kelas dengan menggunakan applikasi WhatsApp Group.

e) Sistem pembelajaran penjas pada masa pandemi

1) SMP Negeri 1 Tanggungharjo

Dalam hasil wawancara dengan kepala sekolah, sistem pembelajaran di SMP N 1 Tanggungharjo pada masa pandemi di lakukan secara daring dan kegiatan belajar mengajar menggunakan applikasi Schoology, WhatsApp dan juga Google Form.

2) MTS Tajul Ulum

Dalam hasil wawancara dengan kepala sekolah, sistem pembelajaran di MTS Tajul Ulum dilakukan secara daring dengan menggunakan applikasi WhatsApp group dan Google Form.

3) SMP Al Ishlah

Dalam hasil wawancara dengan kepala sekolah, sistem pembelajaran di SMP Al Ishlah selama daring menggunakan WhatsApp Group dan untuk anak yang tinggal di pondok pesantren datang ke sekolah.

4) MTS Miftahul Ulum 
Dalam hasil wawancara dengan wakil kepala sekolah, sistem pembelajaran daring di MTS Miftahul Ulum melalui WhatsApp group.

5) SMP IT At Taufiiqiyyah

Dalam hasil wawancara dengan kepala sekolah, sistem pembelajaran daring di SMP IT At Taufiiqiyyah melalui applikasi WhatsApp.

f) Kendala yang di alami guru penjas pada pembelajaran daring

1) SMP Negeri 1 Tanggungharjo

Dari hasil wawancara dengan kepala sekolah dalam kendala yang di alami guru penjas pada saat pembelajaran daring yaitu guru penjas mengalami kendala saat mempraktikan kegiatan-kegiatan praktik pada pembelajaran penjas.

2) MTS Tajul Ulum

Dari hasil wawancara dengan kepala sekolah dalam kendala yang di alami guru penjas pada saat pembelajaran daring yaitu guru penjas mengalami kendala siswa yang tidak memiliki media untuk belajar seperti handphone dan jaringan internet dari siswa yang kurang bagus.

3) SMP Al Ishlah

Dari hasil wawancara dengan wakil kepala sekolah dalam kendala yang di alami guru penjas pada saat pembelajaran daring yaitu guru penjas mengalami kendala siswa yang tidak ikut aktif pada saat pembelajaran berlangsung dan siswa yang tidak memiliki media belajar seperti handphone.

4) MTS Miftahul Ulum

Dari hasil wawancara dengan wakil kepala sekolah dalam kendala yang di alami guru penjas pada saat pembelajaran daring yaitu guru penjas mengalami kendala tidak bisa mempraktikan secara langsung hanya bisa melalui video saja

5) SMP IT At Taufiiqiyyah

Dari hasil wawancara dengan kepala sekolah dalam kendala yang di alami guru penjas pada saat pembelajaran daring yaitu lokasi rumah siswa yang tidak terjangkau jaringan internet dan perilaku siswa yang ber macam-macam.

g) Fasilitas proses pembelajaran daring yang dilakukan oleh sekolah

1) SMP Negeri 1 Tanggungharjo

Dari hasil wawancara dengan kepala sekolah di SMP N 1 Tanggungharjo fasilitas di sekolahan sudah cukup, guru dan siswa di SMP N 1 Tanggungharjo mendapatkan kuota internet.

2) MTS Tajul Ulum

Dari hasil wawancara dengan kepala sekolah di MTS Tajul Ulum siswa dan juga guru mendapatkan kuota internet.

3) SMP Al Ishlah

Dari hasil wawancara dengan kepala sekolah di SMP Al Ishlah fasilitas selama pembelajaran daring di SMP AL Ishlah ada bantuan kuota internet untuk siswa dan alat tulis.

4) MTS Miftahul Ulum

Dari hasil wawancara dengan kepala sekolah di MTS Miftahul Ulum fasilitas di MTS Miftahul Ulum memberikan kuota internet kepada siswa dan guru.

5) SMP IT At Taufiiqiyyah

Dari hasil wawancara dengan kepala sekolah di SMP IT At Taufiiqiyyah fasilitas 
selama pembelajaran daring sudah cukup, karena ada bantuan kuota internet untuk guru dan juga siswa.

2. Guru penjas

a) Seberapa penting pendidikan jasmani di berikan kepada siswa

1) SMP Negeri 1 Tanggungharjo

Dalam hasil wawancara dengan guru penjas pembelajaran penjas di SMP N 1 Tanggungharjo sangat penting, karena pendidikan jasmani olahraga merupakan bagian dari kesehatan tubuh.

2) MTS Tajul Ulum

Dalam hasil wawancara dengan guru penjas, guru penjas MTS Tajul Ulum menaggapi bahwa pembelajaran sangatlah penting karena pendidikan jasmani untuk meningkatkan kesegaran jasmani, rohani, dan kesehatan.

3) SMP Al Ishlah

Dalam hasil wawancara dengan guru penjas di SMP Al Ishlah pembelajaran penjas sangatlah penting karena pembelajaran penjas harus di berikan kepada siswa karena penjas kaitannya dengan kesehatan.

4) MTS Miftahul Ulum

Dalam hasil wawancara dengan guru penjas pembelajaran penjas di MTS Miftahul Ulum sangat penting, karena untuk menjaga kesehatan jasmani dan rohani harus berolahraga.

5) SMP IT At Taufiiqiyyah

Dalam hasil wawancara dengan guru penjas di SMP IT At Taufiqiyah sangatlah penting, karena dengan adanya pembelajaran penjas siswa bisa menjaga tingkat kesehatan.

b) Proses pembelajaran penjasorkes yang ada di sekolah selama pandemi

1) SMP Negeri 1 Tanggungharjo

Dalam hasil wawancara tentang proses pembelajaran penjasorkes guru penjas beranggapan bahwa proses pembelajaran penjas pada masa pandemi dilakukan secara Daring, dengan menggunakan applikasi WhatsApp group dan applikasi Schoology.

2) MTS Tajul Ulum

Dalam hasil wawancara tentang proses pembelajaran penjasorkes guru penjas beranggapan bahwa di MTS Tajul Ulum proses pembelajaran menggunakan WhatsApp Group dan Google Form

3) SMP Al Ishlah

Dalam hasil wawancara tentang proses pembelajaran penjasorkes guru penjas beranggapan bahwa proses pembelajaran penjas pada masa pandemi di SMP Al Ishlah daring dan luring. Pembelajaran luring dilaksanakan untuk anak yang di pondok pesantren karena di pondok tidak boleh memakai handphone dan untuk pembelajaran daring dilaksanakan untuk anak yang tidak tinggal di lingkungan pondok pesantren.

4) MTS Miftahul Ulmum

Dalam hasil wawancara tentang proses pembelajaran penjasorkes guru penjas beranggapan bahwa proses pembelajaran penjas pada masa pandemi dilakukan secara Daring, pelaksanaan pembelajaran daring melalui aplikasi WhatsApp.

5) SMP IT At Taufiiqiyyah

Dalam hasil wawancara tentang proses pembelajaran penjasorkes guru penjas beranggapan bahwa proses pembelajaran penjas pada masa pandemi kurang efektif, karena 
pembelajaran tidak bisa tatap muka secara langsung dan di SMP IT At Taufiqiah selama pembelajaran daring menggunakan aplikasi WhatsApp.

c) Metode yang digunakan selama pembelajaran daring

1) SMP Negeri 1 Tanggungharjo

Hasil wawancara dengan guru penjas terkait dengan metode selama pembelajaran daring yaitu di SMP N 1 Tanggungharjo menggunakan metode kolaborasi (Project Based Learning) dan metode daring.

2) MTS Tajul Ulum

Hasil wawancara dengan guru penjas terkait dengan metode selama pembelajaran daring yaitu di MTS Tajul Ulum menggunakan metode daring selama pembelajaran jarak jauh.

3) SMP Al Ishlah

Hasil wawancara dengan guru penjas terkait dengan metode selama pembelajaran daring yaitu di SMP Al Ishlah selama pembelajaran daring menggunakan metode semi daring.

4) MTS Miftahul Ulum

Hasil wawancara dengan guru penjas terkait dengan metode selama pembelajaran daring yaitu di MTS Miftahul Ulum menggunakan metode kolaborasi (Project Based Learning) dan metode daring.

5) SMP IT At Taufiiqiyyah

Hasil wawancara dengan guru penjas terkait dengan metode selama pembelajaran daring yaitu di SMP IT At Taufiqiyah selama pembelajaran jarak jauh menggunakan metode daring.

d) Pengelolaan kelas selama pembelajaran daring

1) SMP Negeri 1 Tanggungharjo

Dalam hasil wawancara dengan guru penjas pengelolaan kelas selama pembelajaran daring guru penjas di SMP N 1 Tanggungharjo menggunakan cara berinteraksi kepada siswa, dengan berinteraksi kepada siswa, berkomunikasi dan memberikan motivasi kepada siswa.

2) MTS Tajul Ulum

Dalam hasil wawancara dengan guru penjas pengelolaan kelas selama pembelajaran daring guru penjas di MTS Tajul Ulum dengan cara membuat suasana pembelajaran yang nyaman dan memberikan motivasi kepada siswa.

3) SMP Al Ishlah

Dalam hasil wawancara dengan guru penjas pengelolaan kelas selama pembelajaran daring guru penjas di SMP Al Ishlah dengan cara memberikan motivasi kepada siswa agar semangat dalam belajar dan berkomunikasi, membangun komunikasi dengan siswa.

4) MTS Miftahul Ulum

Dalam hasil wawancara dengan guru penjas pengelolaan kelas selama pembelajaran daring guru penjas di MTS Miftahul Ulum dengan cara melalui WhatsApp group memberikan motivasi dan memberikan semangat dalam belajar. Apabila guru penjas tidak bisa berinteraksi dengan siswa secara online guru penjas datang kerumah siswa yang bersangkutan.

5) SMP IT At Taufiiqiyyah

Dalam hasil wawancara dengan guru penjas pengelolaan kelas selama pembelajaran daring guru penjas di SMP IT At Taufiiqiyyah dengan cara guru penjas dalam mengelola kelas dengan cara memberikan motivasi kepada siswa agar semangat dan giat dalam belajar.

e) Sistem proses penilaian pembelajaran penjasorkes pada saat pembelajaran daraing 
1) SMP Negeri 1 Tanggungharjo

Di dalam proses penilaian pada saat pembelajarn daring di SMP N 1 Tanggungharjo pada saat wawancara, guru penjas mengatakan bahwa bahwa sistem penilaian menggunakan metode penilaian tugas mandiri dan audio visual.

2) MTS Tajul Ulum

Di dalam proses penilaian pada saat pembelajarn daring di MTS Tajul Ulum pada saat wawancara, guru penjas mengatakan bahwa sistem penilaian di MTS Tajul Ulum dengan cara mengirimkan video praktik melalui WhtasApp group dan tugas mandiri siswa.

3) SMP Al Ishlah

Di dalam proses penilaian pada saat pembelajarn daring di SMP Al Ishlah pada saat wawancara, guru penjas mengatakan bahwa sistem penilaian yaitu seperti di Rencana Pelaksanaan Pembelajaran K13, penilaian sikap, pengetahuan dan ketrampilan. Dan penilaian praktik di lakukan melalui video.

4) MTS Miftahul Ulum

Di dalam proses penilaian pada saat pembelajarn daring di MTS Miftahul Ulum pada saat wawancara, guru penjas mengatakan bahwa sistem penilaian melalui tugas lembar kerja siswa dan tugas praktik yang kumpulkan dalam bentuk video dan dikirim ke WhatsApp group. Apabila ada siswa yang tidak memiliki handphone guru menyuruh siswa untuk datang kesekolah/bergabung dengan temannya yang memiliki handphone.

5) SMP IT At Taufiiqiyyah

Di dalam proses penilaian pada saat pembelajarn daring di SMP IT At Taufiiqiyyah pada saat wawancara, guru penjas mengatakan bahwa sistem penilaian dengan tugas di lembar kerja siswa dan tugas praktik melalui gambar/video yang di kumpulkan melalui WhatsApp group.

f) Peserta didik merasa senang/tidak bosan pada saat pembelajaran daring

1) SMP Negeri 1 Tanggungharjo

Dalam hasil observasi dan juga wawancara dengan guru penjas pada saat pembelajaran peserta didik merasa bosan dan kurang senang adanya metode pembelajaran daring.

2) MTS Tajul Ulum

Dalam hasil observasi dan juga wawancara dengan guru penjas pada saat pembelajaran peserta didik merasa bosan dengan adanya pembelajaran daring.

3) SMP Al Ishlah

Dalam hasil observasi dan juga wawancara dengan guru penjas pada saat pembelajaran peserta didik merasa bosan dan kurang senang adanya metode pembelajaran daring.

4) MTS Miftahul Ulum

Dalam hasil observasi dan juga wawancara dengan guru penjas pada saat pembelajaran peserta didik merasa senang apabila tugas melalui video karena tugas dari mata pelajaran pendidikan jasmani praktik melalui video dan beda dari mata pelajaran yang lainnya. Dan siswa merasa tidak bosan apabila tugas melalui video.

5) SMP IT At Taufiiqiyyah

Dalam pembelajaran peserta didik merasa bosan karena pelaksanaan pembelajaran hanya melalui apikasi WhatsApp saja dan itu membuat siswa merasa bosan.

g) Kesulitan yang dialami selama pembelajaran daring

1) SMP Negeri 1 Tanggungharjo 
Dalam hasil wawancara dengan guru penjas mengenai kesulitan apa yang dialami selama pembelajaran daring, guru penjas mengalami dengan adanya pembelajaran daring guru menjadi sulit untuk berkomunikasi secara langsung kepada siswa dan sulit membentuk karakter dari siswa.

2) MTS Tajul Ulum

Dalam hasil wawancara dengan guru penjas mengenai kesulitan apa yang dialami selama pembelajaran daring, guru penjas mengalami kesulitan terhadap siswa yang tidak aktif dalam proses pembelajaran, kendala sinyal internet.

3) SMP Al Ishlah

Dalam hasil wawancara dengan guru penjas mengenai kesulitan apa yang dialami selama pembelajaran daring, guru penjas mengalami dengan adanya pembelajaran daring guru menjadi sulit untuk berkomunikasi secapa langsung kepada siswa dan sulit membentuk karakter dari siswa

4) MTS Miftahul Ulum

Dalam hasil wawancara dengan guru penjas mengenai kesulitan apa yang dialami selama pembelajaran daring, guru penjas mengalami kesulitan di siswa yang tidak memiliki sarana prasarana sendiri untuk belajar.

5) SMP IT At Taufiiqiyyah

Dalam hasil wawancara dengan guru penjas mengenai kesulitan apa yang dialami selama pembelajaran daring, guru penjas mengalami kesulitan di siswa yang tidak serius dan mudah bosan pada saat pembelajaran berlangsung.

h) Cara mengatasi kesulitan yang dialami

1) SMP Negeri 1 Tanggungharjo

Cara guru penjas dalam mengatasi kesulitan yaitu dengan berkomunikasi kepada siswa, mengingatkan, dan juga memberi motivasi adalah cara untuk mengatasi kesulitan pada saat pembelajaran daring.

2) MTS Tajul Ulum

Cara guru penjas dalam mengatasi kesulitan yaitu guru penjas mengatakan bahwa dengan menghubungi siswa atau wali murid yang bersangkutan.

3) SMP Al Ishlah

Cara guru penjas dalam mengatasi kesulitan yaitu dengan berkomunikasi kepada siswa, mengingatkan, dan juga memberi motivasi adalah cara untuk mengatasi kesulitan pada saat pembelajaran daring.

4) MTS Miftahul Ulum

Cara guru penjas dalam mengatasi kesulitan yaitu dengan cara guru penjas dalam mengatasi kesulitan yaitu siswa yang tidak memiliki handphone diminta datang langsung ke sekolah dan apabila siswa tersebut dekat dengan rumah temannya, siswa yang bersangkutan bisa meminta tolong kepada teman yang dekat dengan rumahnya.

5) SMP IT At Taufiiqiyyah

Cara guru penjas dalam mengatasi kesulitan yaitu dengan lebih berinteraksi dengan siswa, memberikan motivasi, dan mengenal karakter siswa.

i) Faktor penghambat dalam pembelajaran daring

1) SMP Negeri 1 Tanggungharjo

Dalam hasil wawancara dengan guru penjas faktor yang dialami selama pembelajaran 
daring yaitu yaitu media pada saat pembelajaran dan siswa yang kurang memperhatikan guru pada saat pembelajaran berlangsung.

2) MTS Tajul Ulum

Dalam hasil wawancara dengan guru penjas faktor yang dialami selama pembelajaran daring yaitu kendala sinyal internet dan siswa yang tidak memiliki media pembelajaran seperti handphone.

3) SMP Al Ishlah

Dalam hasil wawancara dengan guru penjas faktor yang dialami selama pembelajaran daring yaitu ada 2 faktor penghambat yaitu di SMP Al Ishlah ada anak yang tinggal di lingkungan pondok pesantren dan ada yang tidak tinggal di pondok pesantren, maka dari itu guru penjas tidak bisa memberika tugas yang sama kepada siswa.

4) MTS Miftahul Ulum

Dalam hasil wawancara dengan guru penjas faktor yang dialami selama pembelajaran daring yaitu alat untuk belajar seperti handphone, jaringan internet yang kurang bagus, dan rasa malas siswa.

5) SMP IT At Taufiiqiyyah

Dalam hasil wawancara dengan guru penjas faktor yang dialami selama pembelajaran daring yaitu kendala jaringan sinyal internet, siswa yang bosan dan kurang bersemangat dalam belajar.

j) Cara menanggapi peserta didik yang kurang aktif

1) SMP Negeri 1 Tanggungharjo

Dalam hasil wawancara dengan guru penjas dalam menganggapi siswa yang kurang aktif yaitu guru memperhatikan siswa, memberikan motivasi, dan memberi penekanan kepada siswa agar semangat dalam belajar.

2) MTS Tajul Ulum

Dalam hasil wawancara dengan guru penjas dalam menganggapi siswa yang kurang aktif yaitu guru menghubungi siswa atau wali murid yang bersangkutan. Dengan cara itu guru mrnjadi tahu apa saja masalah yang di alami siswa sehingga guru bisa memberikan solusi.

3) SMP Al Ishlah

Dalam hasil wawancara dengan guru penjas dalam menganggapi siswa yang kurang aktif yaitu guru menghubungi siswa yang bersangkutan, guru datang langsung ke rumah siswa, dan untuk anak yang tinggal di pondok pesantren guru mendatangi siswa yang bersangkutan guna menanyakan keluh kesah dari siswa.

4) MTS Miftahul Ulum

Dalam hasil wawancara dengan guru penjas dalam menganggapi siswa yang kurang aktif yaitu guru memanggil siswa/wali murid yang bersangkutan untuk datang ke sekolah atau guru datang langsung ke rumah siswa yang bersangkutan.

5) SMP IT At Taufiiqiyyah

Dalam hasil wawancara dengan guru penjas dalam menganggapi siswa yang kurang aktif yaitu dengan cara guru menegur dengan cara memberi motivasi agar siswa tidak malas dan semangat pada saat belajar.

k) Fasilitas di sekolah dalam belajar mengajar selama pembelajaran daring

1) SMP Negeri 1 Tanggungharjo

Dalam hasil wawancara dengan guru penjas di SMP N 1 Tanggungharjo fasilitas 
pembelajaran daring sudah memadai.

2) MTS Tajul Ulum

Dalam hasil wawancara dengan guru penjas di sekolah MTS Tajul Ulum fasilitas pembelajaran daring memberikan kuota internet.

3) SMP Al Ishlah

Dalam hasil wawancara dengan guru penjas di SMP Al Ishlah fasilitas di sekolah sudah memadai, siswa yang ikut pembelajaran daring mendapatkan bantuan kuota internet dan siswa yang tingggal di lingkungan pondok pesantren mendapatkan alat tulis.

4) MTS Miftahul Ulum

Dalam hasil wawancara dengan guru penjas di MTS Miftahul Ulum fasilitas dari sekolah membrikan bantuan kuota internet kepada siswa dan guru.

5) SMP IT At Taufiiqiyyah

Dalam hasil wawancara dengan guru penjas di SMP IT At Taufiqiah fasilitas selama pembelajaran daring diberikan kuota internet untuk siswa dan guru.

Hasil observasi berupa proses belajar mengajar melalui WhatsApp Group dan hasil wawancara yang telah dilakukan peneliti bahwa guru penjas di beberapa sekolah yang sudah diteliti dalam kegiatan belajar mengajar selama pembelajaran daring sangatlah terbatas dan belum berjalan dengan maksimal. Adanya faktor kendala yang membuat kegiatan belajar mengajar menjadi tidak berjalan dengan baik, beberapa kendala pada siswa yang membuat kegiatan belajar mengajar kurang berjalan dengan maksimal yaitu seperti siswa yang tidak memiliki handphone, jaringan internet yang kurang, siswa yang malas saat pembelajaran, siswa yang bosan dan kurang semangat pada saat pemebelajaran daring, siswa yang tidak merespon guru pada saat pembelajaran berlangsung. Kendala lain yang di alami guru penjas dalam pembelajaran daring yaitu guru terbatas dalam mempraktikan kegiatan-kegiatan praktik, pengelolaan kelas yang kurang maksimal apabila dilakukan secara daring.

\section{KESIMPULAN}

Berdasarkan hasil penelitian yang sudah di lakukan oleh peneliti tentang tingkat keaktifan guru penjas dalam pembelajaran penjasorkes pada masa pandemi COVID-19 di SMP/MTS se-Kecamatan Tanggungharjo. Keaktifan guru penjas dalam proses belajar mengajar belum berjalan dengan maksimal. Adanya faktor-faktor penghambat dan juga kekurangan dalam proses belajar mengajar membuat guru penjas mengalami kenala sehingga kegiatan belajar mengajar belum berjalan dengan maksimal. Kendala yang dialami guru penjas dalam pembelajaran daring yaitu guru terbatas dalam mempraktikan kegiatan-kegiatan praktik, pengelolaan kelas yang kurang maksimal apabila dilakukan secara daring. Faktor penghambat dalam proses belajar mengajar pada siswa yang membuat kegiatan pembelajaran kurang maksimal yaitu jaringan internet yang tidak terjangkau yang menyebabkan siswa dalam 
mengikuti pelajaran tidak nyaman, siswa yang tidak memiliki sarana prasarana untuk proses pembelajaran, siswa merasa bosan dengan pembelajaran daring, siswa tidak mengumpulkan tugas dan terlambat dalam mengumpulkan tugas, siswa yang tidak merespon guru pada saat pembelajaran berlangsung. Solusi dari guru penjas yaitu dengan menyarankan siswa untuk berkumpul di rumah teman yang ada jaringan internet/menyuruh siswa untuk datang ke sekolah, bergabung dengan teman yang memiliki handphone, memberikan motivasi, menghubungi siswa/wali murid yang bersangkutan, mendatangi rumah siswa yang bersangkutan.

\section{DAFTAR PUSTAKA}

Dalton, W dan Hari, A.R. (2014). "Modifikasi Model Pembelajaran Sport Education Berbasis Kejuaraan Untuk Guru Penjas SMP.” Jurnal Keolahragaan 2(1):106-18. doi: 10.21831/jk.v2i1.2607.

Irawan, E. dkk . (2021). "Musamus Journal of Physical Education and Sport ( MJPES ) Pengaruh Permainan Tradisional Tapa Gala Untuk Meningkatkan Imunitas Tubuh Siswa SDN Sumi 1 Di Masa Pandemi COVID-19 Abstrak Vol . 03 No . 02 / Musamus Journal of Physical Education and Sport ( MJP.” 03(02):78-88. doi: 10.35724/mjpes.v.

Majid, M.I. (2012). "Survei Keaktifan Anak Tunagrahita Dalam Mengikuti Pembelajaran Pendidikan Jasmani Di SDLB Jepara Tahun 2012.” 1-92.

Noviardila, I. (2020). "Peran Kepala Sekolah Dalam Proses Pembelajaran Di Masa Pandemi Covid19.” Jurnal Bola (Bersama Olahraga Laju Asia) 21(3):1-21.

Pramanda, R. (2020). "Hubungan Dukungan Orang Tua Dengan Motivasi Belajar Siswa Dalam Mengikuti Pembelajaran Penjas Secara Dalam Jaringan (Daring) Saat Pandemi Covid-19 Di Mi Surya Utama Al Fajar Desa Kerep.” Orphanet Journal of Rare Diseases 21(1):1-9.

Taek, B.D. (2019). "Ketrampilan Guru Pendidikan Jasmani Dalam Mengatasi.” Jurnal Sport and Science 2(1).

Zamorano, Z. (2020). "Hambatan Guru PJOK Dalam Meningkatkan Keterampilan Motorik Peserta Didik Pada Masa Pandemi COVID-19 Di Tingkat SMA Se-Kota Magelang." Antimicrobial Agents and Chemotherapy 58(12):7250-57. doi: 10.1128/AAC.03728-14. 